\title{
Septomarginal trabecula and anterior papillary muscle in primate hearts: developmental issues
}

\author{
A. Kosiński ${ }^{1}$, M. Zajączkowski ${ }^{1}$, W. Kuta ${ }^{1}$, D. Kozłowski ${ }^{2}$, M. Szpinda ${ }^{3}$, M. Grzybiak ${ }^{1}$ \\ ${ }^{1}$ Department of Clinical Anatomy, Medical University of Gdansk, Gdansk, Poland \\ $22^{\text {nd }}$ Department of Cardiology, Medical University of Gdansk, Gdansk, Poland \\ ${ }^{3}$ Department of Normal Anatomy, The Ludwik Rydygier Collegium Medicum in Bydgoszcz, Bydgoszcz, Poland
}

[Received 3 January 2013; Accepted 8 February 2013]

\begin{abstract}
The septomarginal trabecula is present in all human hearts as well as in the hearts of other primates. It usually connects the interventricular septum with the anterior papillary muscle, although there are many variations in how this is achieved. The object of the analyses was to estimate the bilateral topography of the septomarginal trabecula and the anterior papillary muscle in the context of the ontogeny and phylogeny of primates. A total of 138 hearts were examined from number of different non-human primates. The presence of the septomarginal trabecula was confirmed in 94.9\% of cases, although not in the hearts of Lemur varius. Four configurations could be distinguished by defining the location of the septomarginal trabecula and its relation to the anterior papillary muscle. For the hearts of the Strepsirrhini and the majority of Platyrrhini neither structure was related, whereas in all examined representatives of Hominoidea they had fused and created morphologically varying forms. On the basis of these results, a concept was developed for the sequence of changes which the topography of the septomarginal trabecula and the anterior papillary muscle undergo during ontogeny and phylogeny. (Folia Morphol 2013; 72; 3: 202-209)
\end{abstract}

Key words: primates, heart, septomarginal trabecula, anterior papillary muscle

\section{INTRODUCTION}

Trabeculae carneae are structures present in the ventricles of the heart, and could be described as morphologically varying muscle fibres which differ in form. They were observed initially in the hearts of birds $[12,18]$. In primates they form a net that gradually multiplies and concentrates to become a complex, multi-layer architectural system [18]. The septomarginal trabecula is one of the trabeculae, one which often has the greatest dimensions and typically forms the connection between the interventricular septum and the anterior right ventricle (RV) wall, as well as with the anterior papillary muscle $[15,18]$.

Apart from an evaluation of the pathophysiological conditions related to the presence of the septomarginal trabecula, a subject of controversy is often the problem of its morphology and phylogeny. It is believed that, along with the crista supraventricularis, it circumscribes the inflow and outflow of the blood, playing an essential role in the mechanism of emptying the RV during the systolic phase [3, 19]. In humans, an overgrowth of the structures often accompanies heart defects and may evoke abnormal haemodynamic phenomena $[13,17]$. Moreover, there have been reports in the literature confirming the presence of conduction system branching within the septomarginal trabecula. This fact explains why ischaemic-based pathologies of the structure may constitute a crucial substrate of conduction disorders in the heart

Address for correspondence: Dr A. Kosiński, Department of Clinical Anatomy, Medical University of Gdansk, ul. Dębinki 1, 80-210, Gdańsk, Poland, tel: +48 5834914 20, fax: +48 58349 14 20, e-mail: akoi@interia.pl 
Table 1. Studied material from hearts of primates

\begin{tabular}{|c|c|c|c|c|c|c|}
\hline Order & Suborder & Infraorder & Superfamily & Family & Species & Total \\
\hline & Strepsirrhini & Lemuriformes & Lemuroidea & Lemuridae & Lemur varius & 7 \\
\hline & & & Lorisoidea & Lorisidae & Nycticebus coucang & 8 \\
\hline & & Platyrrhini & Ceboidea & Cebidae & Cebus capucinus & 11 \\
\hline & & & & & Cebus apella & 3 \\
\hline & & & & & Saimiri sciureus & 8 \\
\hline & & & & & Ateles ater & 3 \\
\hline & & Catarrhini & Cercopithecoidea & Cercopithecidae & Erythrocebus patas & 13 \\
\hline & & & & & Erythrocebus coucang & 2 \\
\hline & & & & & Macaca mulatta & 17 \\
\hline & & & & & $\begin{array}{l}\text { Cercopithecus } \\
\text { grisseoviridis }\end{array}$ & 13 \\
\hline & & & & & Cercocebus galeritus & 1 \\
\hline & & & & & Theropithecus gelada & 2 \\
\hline & & & & & Papio cynocephalus & 28 \\
\hline & & & Hominoidea & Hylobatidae & Hylobateslar & 4 \\
\hline & & & & & Hylobates syndactylus & 4 \\
\hline \multirow[t]{2}{*}{ Primates } & Haplorhini & & & Hominidae & Pan troglodytes & 14 \\
\hline & & & & & & 138 \\
\hline
\end{tabular}

muscle [14]. The septomarginal trabecula and the papillary muscles may vastly hinder the procedures while closing due to low-lying defects in the interventricular septum [11].

There have been very few detailed descriptions of the morphology of the septomarginal trabecula in primates. The literature data, as well as conclusions from our earlier observations on human material, suggest there is a specific sequence of changes that the septomarginal trabecula undergoes during ontogeny. There is a high probability that the development process of the structure is directly connected with the differentiation of the anterior papillary muscle of the RV. Thus, studies on the developmental mechanisms should focus on evaluating the changeability and topography of both elements. The presented material constitutes a continuation of earlier analyses of crista supraventricularis and septomarginal trabecula in human hearts $[8,9]$.

The present work led to the definition of three primary research objectives: 1) evaluating any differentiation of the septomarginal trabecula in selected species of primates; 2) distinguishing individual types with the use of topographic criteria and the relation to the anterior papillary muscle, and 3 ) characterising the process of differentiation of the trabecula in phylogeny.

\section{MATERIALS AND METHODS}

The study was based on material fixed in a formalin-ethanol solution, consisting of 138 hearts from various non-human primates (Table 1). Incisions were made from the top of the RV along its edge side, through the posterior leaflet of the tricuspid valve. Then the right atrium was cut along the inferior periphery of the auricle. After opening the walls of the ventricle and thoroughly removing any remaining blood clots, the interior space was given a comprehensive examination. For smaller hearts a binocular magnifier was used. Especial attention was given to the shape and passage of the septomarginal trabecula through the inside of the ventricle. The establishment of a suitable classification system was achieved by determining the location of the structure in relation to the anterior papillary muscle of the RV. Statistical analysis of the results was performed using Statistica 9.1 software $\left(\chi^{2}\right.$, Kruskal-Wallis). 


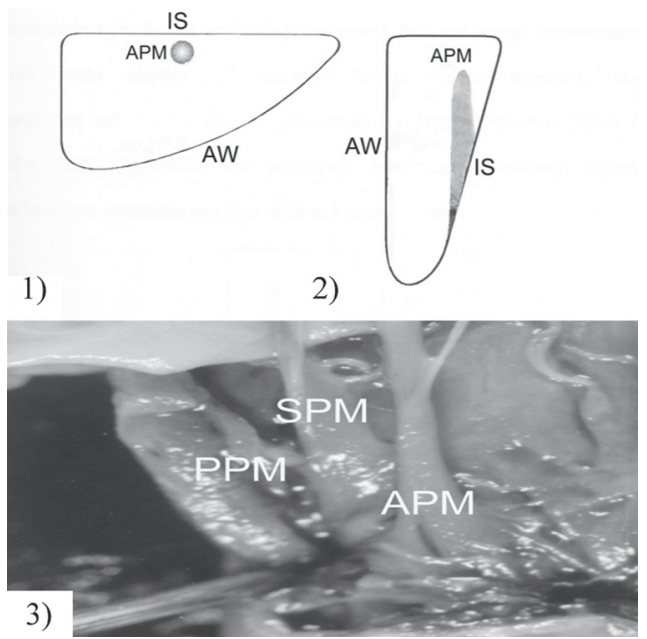

Figure 1. No septomarginal trabecula, Lemur varius, $\left.\sigma^{x} ; 1\right)$ scheme of the right ventricle, top view; 2) scheme of the right ventricle, front view; 3 ) inside of right ventricle, antero-lateral view; APM anterior papillary muscle; SPM — septal papillary muscle; PPM posterior papillary muscle (partially damaged); IS — interventricular septum; AW - anterior wall.

\section{RESULTS}

The presence of the septomarginal trabecula was confirmed in 131 out of 138 individuals (94.9\% of the research material). It was not present at all in the RV of Lemur varius, belonging to the group of Strepsirrhini (7 individuals, Fig. 1), where the anterior papillary muscle grew directly from the interventricular septum. Apart from those hearts in which the septomarginal trabecula was compact and very well developed, there were also a number with relatively thin and poorly developed examples. The structure had various topographic relations with the anterior papillary muscle, the relation being essential for practical reasons, making it possible to distinguish the trabecula from other, sometimes thicker, muscle fibres. On the basis of the passage of the trabecula through the inside of the RV, and especially due to its location in relation to the anterior papillary muscle, 4 types of configuration could be distinguished.

Type I septomarginal trabecula constituted a relatively uniform, continuous structure not connected directly with the anterior papillary muscle (64 hearts, $48.9 \%$ of the hearts with the septomarginal trabecula). The papillary muscle was characterised by a wide variety of form and location, and was often located on a high "scaffolding" of vertical trabeculae originating from the area of the interventricular septum as well as the apex and the interior surface of the anterior wall of the RV. This allowed three subtypes to be distinguished: type la, in which the soaring
A
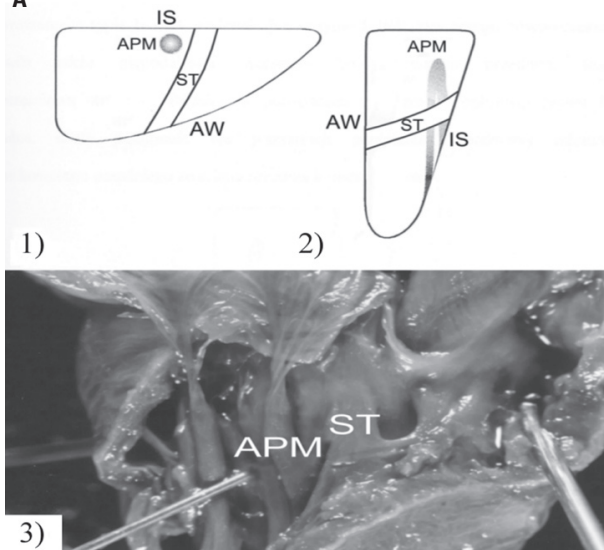

B
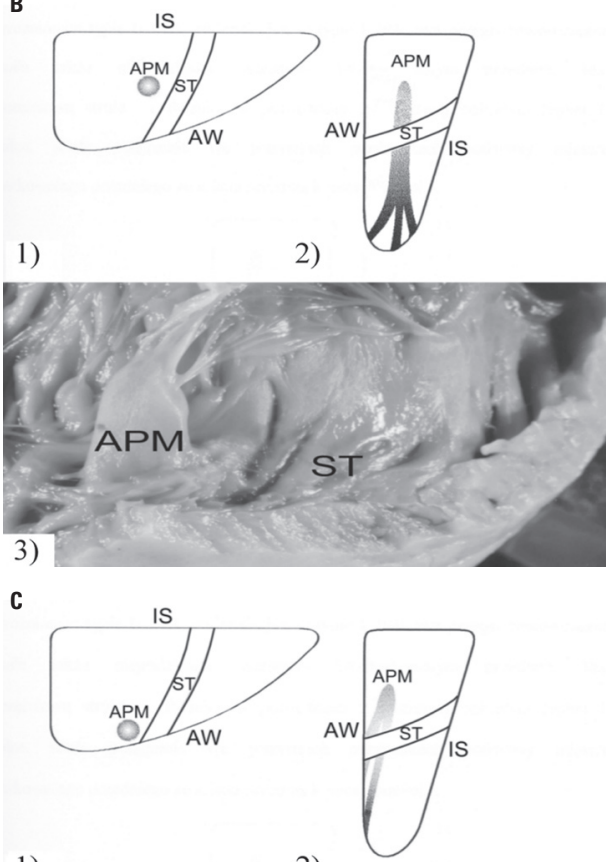

1)

2)

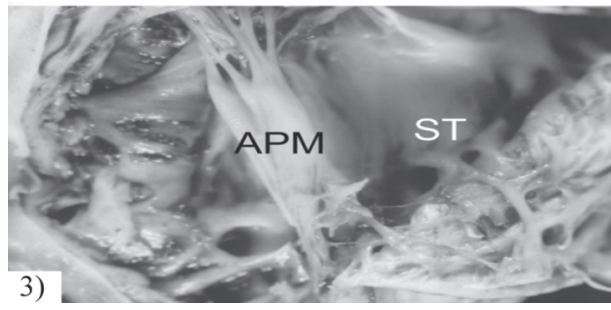

Figure 2. Configuration type: la, Saimiri sciureus, $\mathrm{O}(\mathbf{A})$; lb, Papio cynocephalus, $\sigma^{7}(\mathbf{B})$; Ic, Nycticebus coucang, $\sigma^{\top}(\mathbf{C})$; 1) scheme of the right ventricle, top view; 2) scheme of the right ventricle, front view; 3) inside of right ventricle, antero-lateral view; APM anterior papillary muscle; ST — septomarginal trabecula; IS interventricular septum; AW - anterior wall.

anterior papillary muscle was located at the septum, high on the vertical trabeculae (19 hearts, $14.5 \%$ of the hearts with the septomarginal trabecula, Fig. 2A); type $\mathrm{Ib}$ with the muscle located centrally in the ventricle ( 25 hearts, $19.1 \%$ of the hearts with the septomarginal trabecula, Fig. 2B); and type Ic loca- 
Table 2. Affinity for particular type

\begin{tabular}{|c|c|c|c|}
\hline Without septomarginal trabecula & & Lemur varius & 7 \\
\hline \multirow[t]{3}{*}{ Type I } & $\mathrm{a}$ & $\begin{array}{l}\text { Saimiri sciureus } \\
\text { Cebus capucinus } \\
\text { Cebus apella } \\
\text { Erythrocebus patas } \\
\text { Macaca mulatta }\end{array}$ & $\begin{array}{c}4 \\
5 \\
3 \\
5 \\
2 \\
19\end{array}$ \\
\hline & $b$ & $\begin{array}{l}\text { Nycticebus coucang } \\
\text { Cebus capucinus } \\
\text { Erythrocebus patas } \\
\text { Macaca mulatta } \\
\text { Cercopithecus grisseoviridis } \\
\text { Papio cynocephalus } \\
\text { Cercocebus galeritus }\end{array}$ & $\begin{array}{c}2 \\
4 \\
6 \\
8 \\
3 \\
1 \\
1 \\
25\end{array}$ \\
\hline & $c$ & $\begin{array}{l}\text { Nycticebus coucang } \\
\text { Saimiri sciureus } \\
\text { Ateles ater } \\
\text { Cercopithecus grisseoviridis } \\
\text { Papio cynocephalus }\end{array}$ & $\begin{array}{c}5 \\
4 \\
3 \\
6 \\
2 \\
20\end{array}$ \\
\hline Type II & & $\begin{array}{l}\text { Erythrocebus coucang } \\
\text { Theropithecus gelada } \\
\text { Nycticebus coucang }\end{array}$ & $\begin{array}{l}2 \\
1 \\
1 \\
4\end{array}$ \\
\hline \multirow[t]{2}{*}{ Type III } & a & $\begin{array}{l}\text { Papio cynocephalus } \\
\text { Hylobates lar } \\
\text { Hylobates syndactylus } \\
\text { Pan troglodytes }\end{array}$ & $\begin{array}{c}7 \\
3 \\
3 \\
6 \\
19\end{array}$ \\
\hline & $b$ & $\begin{array}{l}\text { Cebus capucinus } \\
\text { Macaca mulatta } \\
\text { Hylobates lar } \\
\text { Papio cynocephalus } \\
\text { Theropithecus gelada }\end{array}$ & $\begin{array}{c}2 \\
2 \\
1 \\
7 \\
1 \\
13\end{array}$ \\
\hline \multirow[t]{4}{*}{ Type IV } & a & $\begin{array}{l}\text { Macaca mulatta } \\
\text { Papio cynocephalus } \\
\text { Hylobates syndactylus }\end{array}$ & $\begin{array}{l}5 \\
3 \\
1 \\
9\end{array}$ \\
\hline & $b$ & $\begin{array}{l}\text { Cercopithecus grisseoviridis } \\
\text { Papio cynocephalus } \\
\text { Pan troglodytes }\end{array}$ & $\begin{array}{c}3 \\
5 \\
6 \\
14\end{array}$ \\
\hline & c & $\begin{array}{l}\text { Erythrocebus patas } \\
\text { Cercopithecus grisseoviridis } \\
\text { Papio cynocephalus } \\
\text { Pan troglodytes }\end{array}$ & $\begin{array}{l}2 \\
1 \\
3 \\
2 \\
8\end{array}$ \\
\hline & & & 138 \\
\hline
\end{tabular}

ted at the anterior wall of the ventricle (20 hearts, $15.3 \%$ of the hearts with the septomarginal trabecula, Fig. 2C). Type I was significantly more common in Strepsirrhini (Nycticebus coucang) and Platyrrhini; there was no significant difference between these groups in the frequency of type I $\left(\chi^{2}\right.$ test $=0.15$; $\mathrm{df}=1, \mathrm{p}=0.700$ ) (Table 2).

In types II and III the septomarginal trabecula also constituted a uniform, one-piece structure, not divided by the anterior papillary muscle. In comparison 


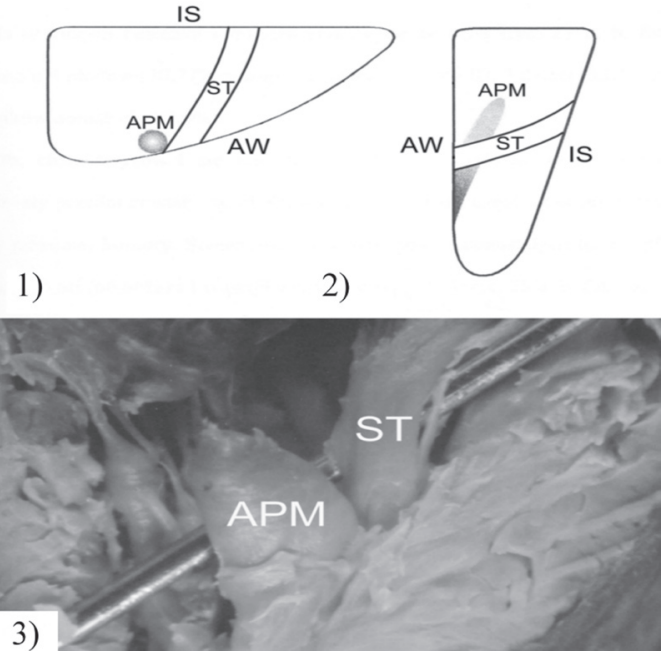

Figure 3. Configuration type II, Erythrocebus coucang, $0^{\text {; }}$; 1) scheme of the right ventricle, top view; 2) scheme of the right ventricle, front view; 3 ) inside of right ventricle, antero-lateral view; APM anterior papillary muscle; ST — septomarginal trabecula; IS interventricular septum; AW — anterior wall.

with type I the difference included: 1) a firm connection between the base of the anterior papillary muscle and the anterior wall of the RV in all cases, and 2) its direct relation with the septomarginal trabecula. The contact position for both structures was described as type II (4 hearts, $3.0 \%$ of all hearts with the septomarginal trabecula, Fig. 3), whereas their permanent fusion was described as type III (32 hearts, $24.4 \%$ of the hearts with the septomarginal trabecula). In this type, the corpus of the muscle connected to the anterior wall was firmly integrated with the peripheral, parietal end of the septomarginal trabecula. Taking into account the height of the junction, 2 subtypes were distinguished for type III. Type IIIa, in which the trabecula reached approximately half the height of the muscle, was observed in 19 hearts (14.5\% of the hearts with the septomarginal trabecula, Fig. 4A). In type IIIb, both structures were connected at the base of the anterior papillary muscle (Fig. 4B). Its presence was observed in 13 hearts $(9.9 \%$ of the hearts with the septomarginal trabecula).

Cases in which 2 parts of the septomarginal trabecula could be distinguished were classified as type IV: septopapillar, connecting interventricular septum with the anterior papillary muscle, and papillomarginal between the muscle and the anterior wall of the RV. This type was observed in 31 hearts $(23.7 \%$ of the hearts with the septomarginal trabecula). The septopapillary part consisted of a uniform, well-developed segment of the septomarginal trabecula,
A

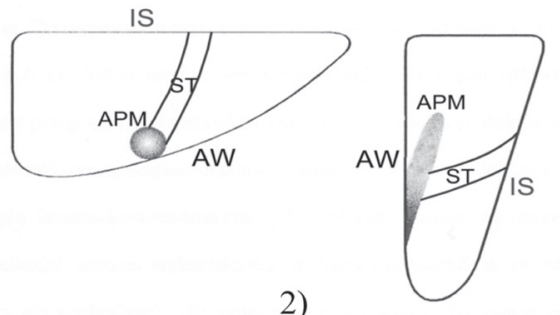

1)

2)
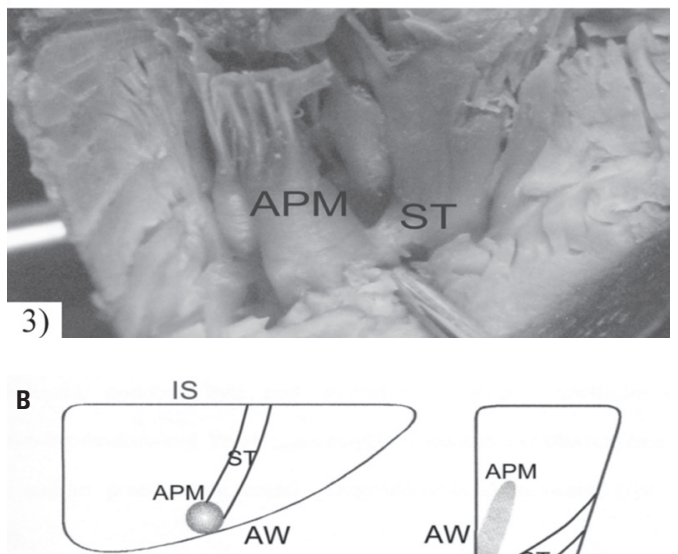

1)

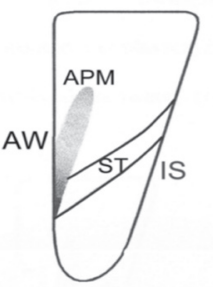

2)

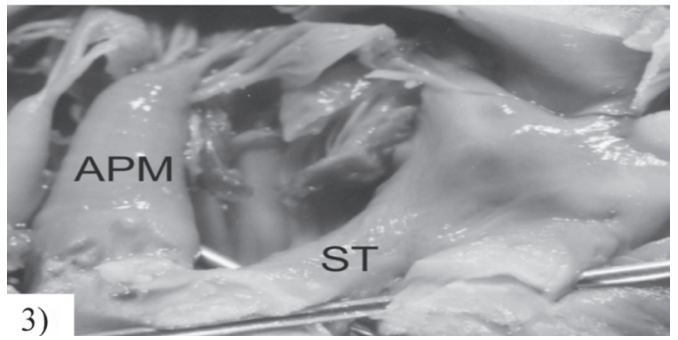

Figure 4. Configuration type: Illa, Papio cynocephalus, $\mathrm{O}^{7}(\mathbf{A})$; Illb, Macaca mulatta, $O$ (B); 1) scheme of the right ventricle, top view; 2) scheme of the right ventricle, front view; 3 ) inside of right ventricle, antero-lateral view; APM - anterior papillary muscle; ST — septomarginal trabecula; IS — interventricular septum; AW - anterior wall.

whereas the papillomarginal part was characterised by a wide variety in both the degree of development and topography. Taking into account these facts, three subtypes were distinguished. In type IVa, the centrally located anterior papillary muscle parted the septomarginal trabecula into 2 segments. The singular, compact papillomarginal part was similar to the septopapillary part in terms of its length and size. In most cases it was positioned horizontally in the ventricle to form an extension of the septopapillary part (Fig. 5A). This form was observed in 9 hearts $(6.9 \%$ of the hearts with the septomarginal trabecula). In type IVb, the well-developed and also horizontal septopapillary part was firmly connected at 
A

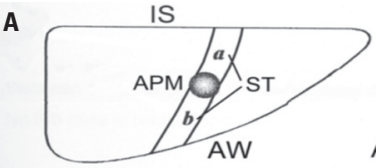

1)

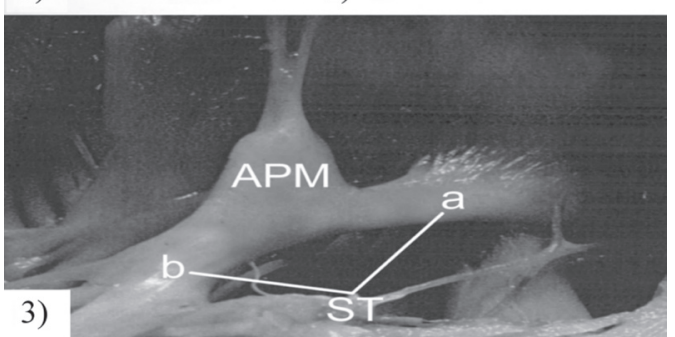

B

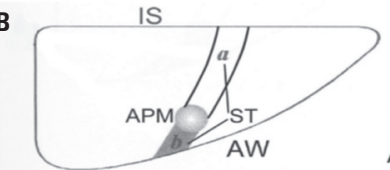

1)

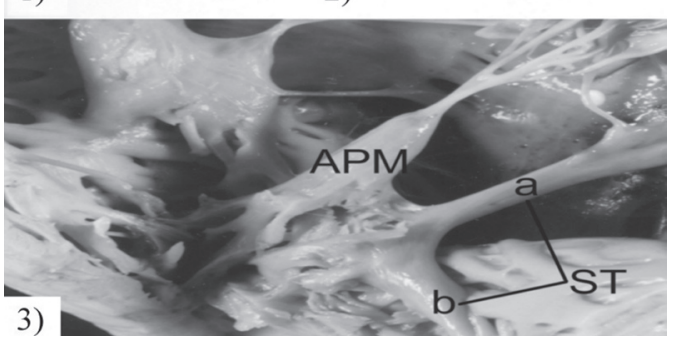

C

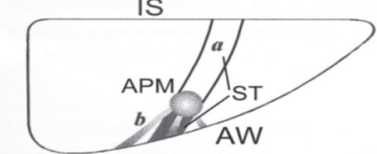

1)

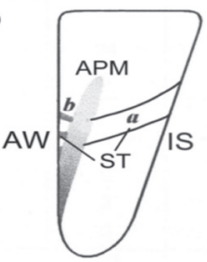

2)

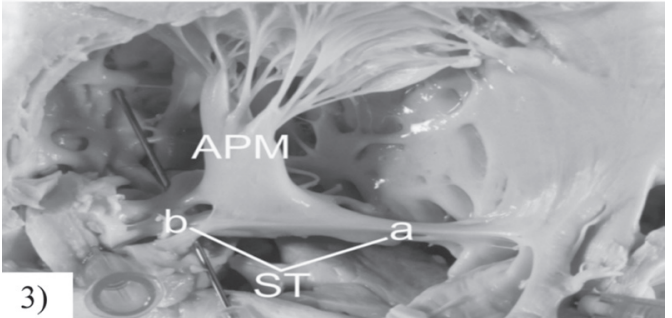

Figure 5. Configuration type: IVa, Papio cynocephalus, $\sigma^{7}(\mathbf{A}) ; \mathrm{IVb}$, Pan troglodytes, $\mathbf{O}^{\top}(\mathbf{B})$; IVc, Pan troglodytes, $\mathrm{O}^{\top}$ (C); 1) scheme of the right ventricle, top view; 2) scheme of the right ventricle, front view; 3) inside of right ventricle, antero-lateral view; APM — anterior papillary muscle; ST — septomarginal trabecula: a septopapillary part; $\mathrm{b}$ - papillomarginal part; IS — interventricular septum; AW — anterior wall. one end to the anterior papillary muscle, located more parietally. The papillomarginal part of the trabecula rose steeply from its base, towards the anterior wall, to the apex of the ventricle. It was comparable to the septopapillary part, while being well-developed and radically different from other morphologic elements of the RV (Fig. 5B). In the examined material this type occurred in 14 cases $(10.7 \%$ of the hearts with the septomarginal trabecula). Type IVc typically had a well-developed, compact part, horizontally cutting the inside of the ventricle septopapillary. By contrast, the papillomarginal part constituted a morphologically non-uniform structure, characterised by extensive variety in its size and location, as well as the number of the trabeculae branching from the muscle (Fig. 5C). In most cases there were several short muscles branching from around its base towards the anterior wall, both radially and indirectly. This form was observed in 8 hearts $(6.1 \%$ of the hearts with the septomarginal trabecula).

Statistically significant differences were observed between the examined groups of primates in terms of frequency of septomarginal trabecula types (Kruskal-Wallis test: $\mathrm{H}=54.81390 ; \mathrm{df}=3 ; \mathrm{n}=138 ; \mathrm{p}<$ $<0.0001$ ). Types III and IV in the Hominoidea group were the only ones to feature the observed variations. There were no statistically significant differences in any type of Cercopithecoidea.

\section{DISCUSSION}

The septomarginal trabecula, since it occurs in all human hearts as well as in other primate hearts, is formed from the muscle strip of the interventricular septum. It lies between the underside of the end of the crista supraventricularis and the anterior ventricle wall $[18,20]$. By its topography it may resemble the false chordae tendineae observed in both ventricles, whose arrhythmogenic role is sometimes questioned $[5,10]$. The term septomarginal trabecula was first introduced by Tandler [20], based on the location of the attachments: initial (nearer-septal) and final (further-parietal, marginal). He described the trabecula, speculating on its homology with the muscle strip present in reptile hearts. Beninghoff [2] was the first to distinguish its two parts: septopapillary and papillomarginal.

In veterinarian terminology and zoological textbooks there exist a varied set of nomenclature concerning the 
septomarginal trabecula. Some authors do not distinguish the structure at all, whereas they describe compact bands having a fibrous-muscular character connecting different parts of the RV, including the connection between the interventricular septum and the anterior papillary muscle [1, 4, 7]. Hofer et al. [6] presenting his own collective observations and those of Fiedler, Davis and Fick, invariably uses the term septomarginal trabecula. He observed that it does not occur in lemurs or is poorly developed, in Nycticebus coucang it is a well-developed structure with the anterior papillary muscle located at the anterior wall of the RV, while in Platyrrhini and Catarrhini it varies significantly. Similar conclusions were drawn from our analysis.

We realise that the material we examined was characterised by a relative non-uniformity and contained a comparative low number of groups. Due to difficulties in acquiring the material, it has taken many years to even reach this point. As it has been mentioned, similar analyses of human hearts had been performed previously [9]. Comparing our data with the previous results facilitated the interpretation of some phenomena taking place both during the ontogeny and phylogeny of primates. During our studies, only in the lemur heart did we not observe a septomarginal trabecula, and in these cases the anterior papillary muscle grew directly out of the ventricular septum. This is consistent with the observations of Hofer et al. [6] and of Szostakiewicz-Sawicka $[18,19]$. During comparisons of earlier analyses of human material, it was apparent that the essential morphological differentiation of the trabecula in other primates needs to be stressed. In humans, irrespective of their age, it was always a distinct muscle structure, while in animal hearts it was characterised by substantial variety both in size and shape. It sometimes resembled a thick false chorda tendinea and hence, as Tandler [20] confirms, the 2 forms may be confused. The architecture of the RV structures, and especially the bilateral topography of the septomarginal trabecula and the anterior papillary muscle, provided a foundation for distinguishing certain types of configurations. The proposed classification takes into account the morphological diversity of the trabecula itself by selecting the septopapillary and the papillomarginal parts, as suggested by other authors. However the classification may not appear to be particularly intuitive, it might reflect the processes taking place both during ontogeny and phylogeny.
Diversification of the topography of the anterior papillary muscle seems to have an evolutionary foundation. Puff and Goerttler [16] observed in $12 \mathrm{~mm}$ human embryos that the anterior papillary muscle is tightly grown together with the interventricular septum and seems to emerge from it, while they did not observe the septomarginal trabecula inside the RV. In other, larger embryos the anterior papillary muscle was centrally located and connected with the septum by means of a fibrous-muscular stripe which was recognised as the septopapillary part of the septomarginal trabecula. In $10 \mathrm{~mm}$ hearts of 12 foetuses the configuration was similar, with a tendency towards a more parietal, peripheral location of the muscle. The data confirms its gradual "migration" at a very early stage of prenatal life, from the septal location, through the centre, to the parietal one. At this point the septomarginal trabecula is formed, and then both structures fuse in the area of the anterior wall of the RV. The final configuration matches our definition for type III.

The comparison of the analyses performed on human and animal material resulted in some interesting observations [9]. In human hearts, type I was rarely observed, being exclusively related to foetal and child hearts, and only with the parietal location of the anterior papillary muscle (Ic). In other primates, however, it was a commonly observed type, with all configurations of muscle location $(a, b, c)$. While it related to all Strepsirrhini Nycticebus coucang, and very often to Platyrrhini, it was not observed in Hominoidea. The septomarginal trabecula merged with the anterior papillary muscle was predominant in human hearts (types III and IV). A curious fact is that while type III (one-piece trabecula) was observed with similar frequency in foetal, child and adult hearts, type IV (2-piece trabecula) was rarely observed in foetal, occasionally in child and very often in adult hearts. This may be evidence that the 2-piece structure of the septomarginal trabecula is formed during ontogeny. Thus type Illa might be a starting point both for IVa and for IVc. It seems that the condition required for them to develop is the disproportion between 2 phenomena: extending (or remodelling) the RV, with a simultaneous, compensational lengthening of the septomarginal trabecula. In such cases, as a result of the retraction of the anterior papillary muscle, and depending on the intensity of the process, type IVa may be formed (the muscle being "pulled more" by the trabecula), or 
type IVc (the muscle being "pulled less"). According to this concept, in the former type the septopapillary part constitutes the proper septomarginal trabecula, whereas the papillomarginal part originates from the structure of the anterior papillary muscle. In the latter case, as previously stated, the septopapillary part is the proper septomarginal trabecula, whereas the muscle remains typically fixed within the ventricle wall as a result of a less intensive retraction. All that develops is a morphologically non-uniform papillomarginal part, being a conglomerate of muscle bands, connecting the free segment of the muscle corpus with the anterior wall of the RV. However, type IIIb may serve as a starting point for type IVb. A postulated mechanism is that the marginal end of the trabecula fuses with the anterior papillary muscle on a longer segment.

The current analysis, though based on human material, has some use in the context of other primate hearts, with types III and IV being well represented. It is interesting that their morphologic criteria were met by all Hominoidea, while none of the Strepsirrhini. Since the studies referred to adult individuals exclusively, it is difficult to speculate on the course of events in the ontogeny. Nevertheless, it seems that the current concept for the conversion of certain types may be implemented in this case.

Type II, which occurred infrequently in animal hearts, should be treated rather as an intermediate form. This is demonstrated by the results of studies made on human material, where, apart from the contact location of the anterior papillary muscle in relation to the septomarginal trabecula, partially fused forms were also observed [9].

The septomarginal trabecula along with the anterior papillary muscle constitutes a specific morphologic conglomerate, whose versatile configuration facilitates the interpretation of developmental mechanisms. Due to the vast scope of observations, a detailed anatomic characteristic of the structures was developed separately. The studies will be continued via microscopic analysis.

\section{REFERENCES}

1. Armiger LC, Urthaler F, James TN (1979) Morphological changes in the right ventricular septomarginal trabecula (false tendon) during maturation and ageing in the dog heart. J Anat, 129: 805-817.
2. Benninghoff A (1942) Lehrbuch der Anatomie des Menschen. JF Lehmanns, Berlin.

3. Brandt W (1957) The closing mechanism of the tricuspidal valve in the human heart. Acta Anat, 30: 128-132.

4. Gerlis LM, Wright HM, Wilson N (1984) Left ventricular bands. A normal anatomical feature. Br Heart J, 52: 641-647.

5. Gueron M, Cohen W (1972) Anomalous left ventricular chordae tendineae and pre-excitation. Unusual cause of praecordial pansystolic murmur in a baby with fibroelastosis. Br Heart J, 34: 966-968.

6. Hofer H, Schultz AH, Strock D (1960) Primatologia. S Karger, Basel.

7. Holmes $\mathrm{AH}$ (1921) The auriculo-ventricular bundle in mammals. J Anat, 55: 269-285.

8. Kosiński A, Nowiński J, Kozłowski D, Piwko G, Kuta W, Grzybiak M (2007) The crista supraventricularis in the human heart and its role in the morphogenesis of the septomarginal trabecula. Ann Anat, 189: 447-456.

9. Kosiński A, Kozłowski D, Nowiński J, Lewicka E, Dąbrowska-Kugacka A, Raczak G, Grzybiak M (2010) Morphogenetic aspects of the septomarginal trabecula in the human heart. Arch Med Sci, 6: 733-743.

10. Lotkowski D, Grzybiak M, Kozłowski D, Budzyn K, Kuta W (1997) A microscopic view of false tendons in the left ventricle of the human heart. Folia Morphol, 56: 31-39.

11. Loukas M, Klaassen Z, Tubbs RS, Derderian T, Paling DAN, Chow D, Patel S, Anderson RH (2010) Anatomical observations of the moderator band. Clin Anat, 23: 443-450.

12. Lu Y, James TN, Bootsma M, Terasaki F (1993) Histological organization of the right and left atrioventricular valves of the chicken heart and their relationship to the atrioventricular Purkinje ring and the middle bundle branch. Anat Rec, 235: 74-86.

13. Maron BJ, Mclntosh CL, Klues HG, Cannon RO $3^{\text {rd }}$, Roberts WC (1993) Morphologic basis for obstruction to right ventricular outflow in hypertrophic cardiomyopathy. Am J Cardiol, 71: 1089-1094.

14. Okabe M, Fukuda K, Nakashima Y, Hiroka T, Arakawa K, Kikuchi M (1991) A quantitative histopathological study of right bundle branch block complicating acute anteroseptal myocardial infarction. Br Heart J, 65: 317-321.

15. Podlecki K (1987) Morphology of the anterior papillary muscle in the right ventricle in human heart. Folia Morphol, 46: 187-196.

16. Puff A, Goerttler U (1963) Die Entwicklung der grossen Papillarmuskels der rechten Kammer unter besonderer Berücksichtigung der Bildung der Einströmungsbahn. Morph Jb, 105: 292-316.

17. Rowland TW, Rosenthal A, Castaneda AR (1975) Double chamber right ventricle: experience with 17 cases. Am Heart J, 89: 455-462.

18. Szostakiewicz-Sawicka H (1967) The right atrio-ventricular valve in Primates. Acta Biol et Med Soc Sc Gedan, 11: 545-636.

19. Szostakiewicz-Sawicka H (1968) The anterior papillary muscle of the right ventricle. Folia Morphol, 27: 427-439.

20. Tandler J (1913) Anatomie des Herzens. G Fischer, Jena. 